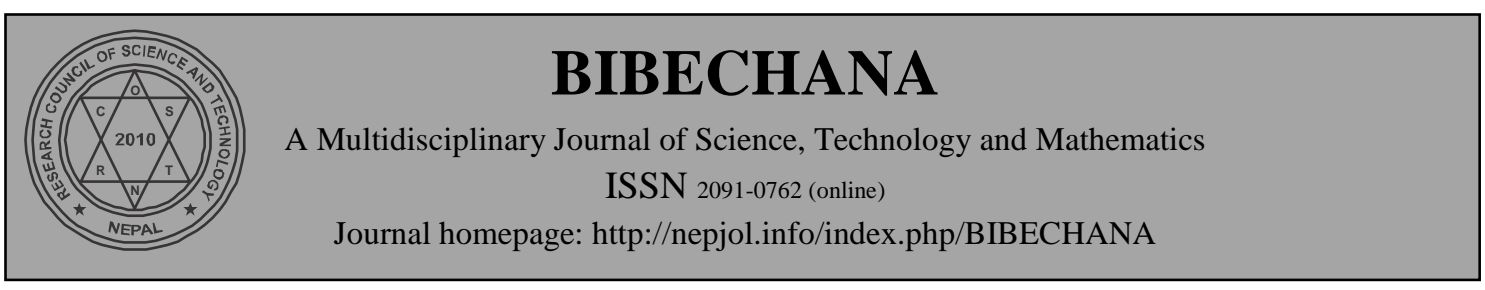

\title{
Dye-sensitized solar cells sensitized with natural dye extracted from Indian Jamun
}

\author{
Indra B. Karki ${ }^{1,2 *}$, Jeevan J. Nakarmi ${ }^{1}$, Pradeep K. Mandal ${ }^{2}$, Suman Chatterjee ${ }^{2}$ \\ ${ }^{1}$ Central Department of Physics, Tribhuvan University, Kathmandu, Nepal \\ ${ }^{2}$ Department of Physics, University of North Bengal, Siliguri-734013, India \\ *Corresponding author: E-mail: indrakarky@gmail.com
}

Accepted for publication: February 06, 2014

\begin{abstract}
Dye sensitized solar cell (DSSC) is a device which absorbs light from the sun with a layer of dye molecules and directly converts into electric energy. DSSCs based on ZnO have drawn attention worldwide due to their low cost and easy preparation techniques compared to conventional silicon based photovoltaic devices. Silicon based solar cells were the most popular before the emerging of dye-sensitized solar cells. These silicon based solar cells devices have dominated photovoltaic industry until now.

The objectives of this study is to make DSSC using $\mathrm{ZnO}$ on ITO coated glass substrate as anode and characterize the DSSC properties such as conversion efficiency, short current density, open circuit voltage, and fill factor. $\mathrm{ZnO}$ thin films have been prepared on Indium tin oxide (ITO) glass substrate. These films were used to construct ITO/ZnO/Natural Dye/C/ITO, DSSCs with natural anthocyanin sensitizer extracted from wild Jamun fruits. The cells show open circuit voltage (Voc) of $0.58 \mathrm{~V}$, short-circuit current (I sc) of $1.66 \mathrm{~mA}$ and 0.58 fill factor (FF) with an conversion efficiency $(\eta)$ of $1.23 \%$.
\end{abstract}

(C) 2014 RCOST: All rights reserved.

Keywords: Dye Sensitized Solar Cells; ZnO; Jamun natural dyes; Electrolyte.

\section{Introduction}

Dye sensitized solar cell (DSSC) is third generation and environmental friendly dye based solar cell. It is the most suitable candidate for the next generation of building integrate photovoltaics [1]. Although a light-to-energy conversion exceeding $12 \%$ has been achieved with a liquid electrolyte [2], several practical factors such as the leakage or volatilization of the liquid solvent are still limiting their long term stability and industrial application [3]. It is a device which absorbs light from the sun with a layer of dye molecules and directly converts into electric energy. Gratzel and O'Regan found dye-sensitized solar cells (DSSC), which are regarded as the latest technology in solar cells, in 1991 [4]. For this reason, such cell is called Gratzel cell. The interest in the DSSC has increased with this development. The vision is to produce DSSC from cheap materials in low-cost processes, thus resulting in low-cost electricity production from solar radiation [5].

DSSCs are generally considered much more environmentally benign to produce than conventional silicon-based solar cells because they use relatively non-toxic materials that require little energy to manufacture. Silicon is the primary material comprising today's solar cells. In the manufacturing of most solar cells, silica $\left(\mathrm{SiO}_{2}\right)$ must be heavily heated to separate the silicon from oxygen, so that it can be 
I.B. Karki et al. / BIBECHANA 11(1) (2014) 34-39: (Online Publication: March, 2014) p.35

further processed into a solar cell. Processing silica to produce silicon is an energy-intensive process. At current efficiencies, it takes years for a conventional solar cell to generate as much energy as was used to make the silicon it contains.

Recently, some research groups have achieved conversion efficiencies of 11-12 \%, for $\mathrm{TiO}_{2}$ based dyesensitized solar cells with inorganic dyes [6-7]. However, these cells still suffer from a high recombination rate between the injected electrons and the oxidized dye or ions in solution. The high recombination rate in DSSCs is attributed to the small size of the particles, which cannot establish significant band banding [8-12]. That is, an electric field that spatially separates the injected electrons from the holes in the dye or solution is not formed at the electrode-electrolyte interface [10]. Until now, the major part of the photoanode DSSC research has mainly focused on $\mathrm{TiO}_{2}$ nanostructures. However, $\mathrm{ZnO}$ semiconductor can be a good alternative as it can exhibit several advantages in comparison with $\mathrm{TiO}_{2}$ semiconductor, such as a direct band gap $(3.37 \mathrm{eV})$, higher exciton binding energy (60 meV) compared to $\mathrm{TiO}_{2}(4 \mathrm{meV})$, and higher electron mobility $\left(200 \mathrm{~cm}^{2} \mathrm{~V}^{-1} \mathrm{~s}^{-1}\right)$ over $\mathrm{TiO}_{2}\left(30 \mathrm{~cm}^{2} \mathrm{~V}^{-1} \mathrm{~s}^{-1}\right)$ for similar band gap energy levels [13-14]. In case of natural dye and $\mathrm{ZnO}$ thin film based DSSC solar cell, researchers have achieved efficiencies of less than $2 \%$ till date [15-16]. Recently we successfully [17] demonstrated $\mathrm{ZnO}$ nanorod based DSSCs with various dyes.

The purpose of this study is to identify the significant $I-V$ curve parameters aspects of the nanocrystalline $\mathrm{ZnO}$ based DSSC using natural dyes. The knowledge of the significant $I-V$ curve parameters aspects will be used as input in further research to increase the efficiency of DSSC and support the development of solar cells as a sustainable alternative for generating electric energy. In this work, we report significant $I$ $V$ curve parameters and efficiency aspects of the nanocrystalline ZnO based DSSC using natural dye Jamun. The coated nanoporous electrode was examined by means of current voltage dependence $(I-V)$ of the DSSC solar cell when illuminated and in the dark.

\section{Materials and Method}

\section{Experimental Section}

\subsection{Synthesis of $\mathrm{ZnO}$ nanorods thin film and counter electrode}

$\mathrm{ZnO}$ nanorods were synthesized using sol-gel spin coating technique. In this process, we prepared $5 \mathrm{mM}$ solution of Zinc acetate dehydrate, $\left(\mathrm{CH}_{3} \mathrm{COO}\right)_{2} \mathrm{Zn}, 2 \mathrm{H}_{2} \mathrm{O}$, (98\% Merck) with methanol. The solution was spun on indium tin oxide (ITO) coated glass substrate at $1000 \mathrm{rpm}$ for 30s. The Zinc acetate solution is spread on a rotating substrate according to [18-19]. The substrates were heated to $350^{\circ} \mathrm{C}$ in conventional oven for $30 \mathrm{~min}$ to yield layers of $\mathrm{ZnO}$ islands with their (100) plane parallel to the substrate surface. After evaporation of solvent, a thin $\mathrm{ZnO}$ film was formed as shown in flow chart in figure 1 . The process was repeated for five to seven times to control the thickness of the film. Concentration of the solution and spinning speed of the substrate also play important roles in adjusting the thickness of the fabricated film.

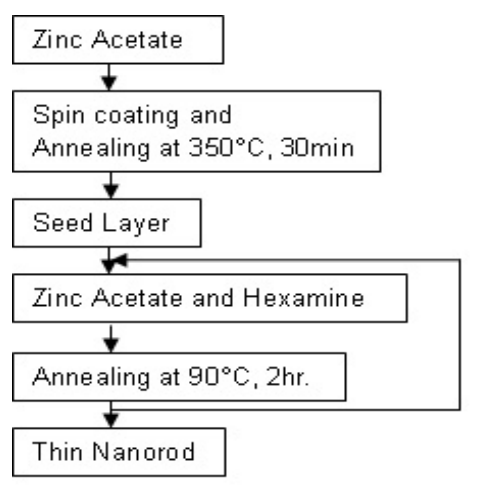

The counter electrode (cathode) is prepared on another ITO coated glass by using amorphous carbon dust.

\subsection{DSSC assembling}

DSSCs were assembled following the procedure described in the literature [19]. The amorphous carbon coated counter electrode was placed on the top so that the conductive side of the counter electrode faces the $\mathrm{ZnO}$ film. The iodide based solution as the liquid electrolyte $(0.5 \mathrm{M}$ potassium iodide mixed with $0.05 \mathrm{M}$ iodine in water-free ethylene glycol) was placed at the edges of the plates. The liquid electrolyte was drawn into the space between the electrodes by capillary action. Two binder clips were used to hold the electrodes together as shown in figure 2 (a) \& 2(b).

Figure 1: Flow Chart - Preparation of $\mathrm{ZnO}$ nanorod 
I.B. Karki et al. / BIBECHANA 11(1) (2014) 34-39: (Online Publication: March, 2014) p.36
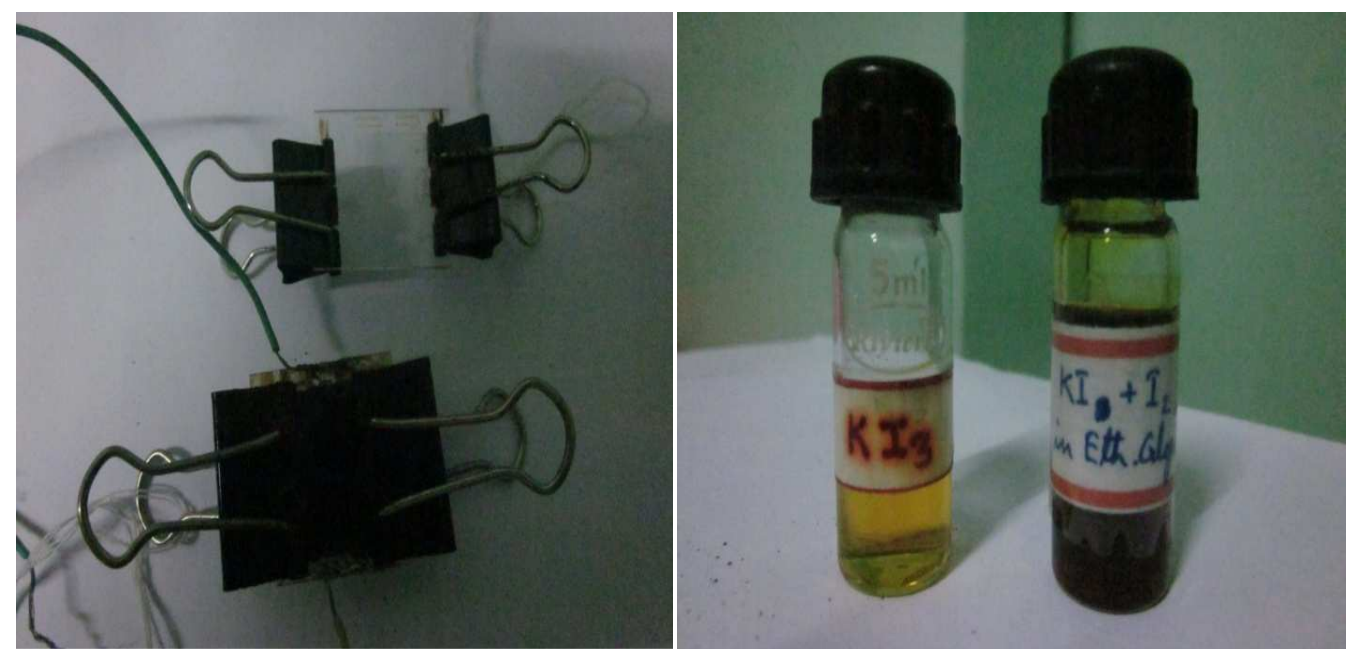

Figure 2 : (a) ZnO nanorods based DSSCs with natural dyes (b) Liquid Electrolyte $\mathrm{KI}_{3}$.

\section{Results and Discussion}

The morphology of the $\mathrm{ZnO}$ samples was observed using a scanning electron microscope (SEM) with a field emission gun operating at $200 \mathrm{kV}$. Figure 3 displays $\mathrm{ZnO}$ nanorod seeds and grow arrays in a wide surface area. The nanorods have an average length of $600 \mathrm{~nm}$ diameter ranging from 100 to $200 \mathrm{~nm}$ and they are mostly vertically aligned with the substrate having hexagonal shapes. The thickness of $\mathrm{ZnO}$ film was around $\sim 50 \mu \mathrm{m}$.

The solar conversion efficiency $(\eta)$ of a DSSC can be estimated using the conversion efficiency formula:

$$
\eta=\frac{P_{\max }}{P_{\text {in }}}
$$

where $P_{\max }$ and $P_{\text {in }}$ denote the maximum output power and the input power respectively.

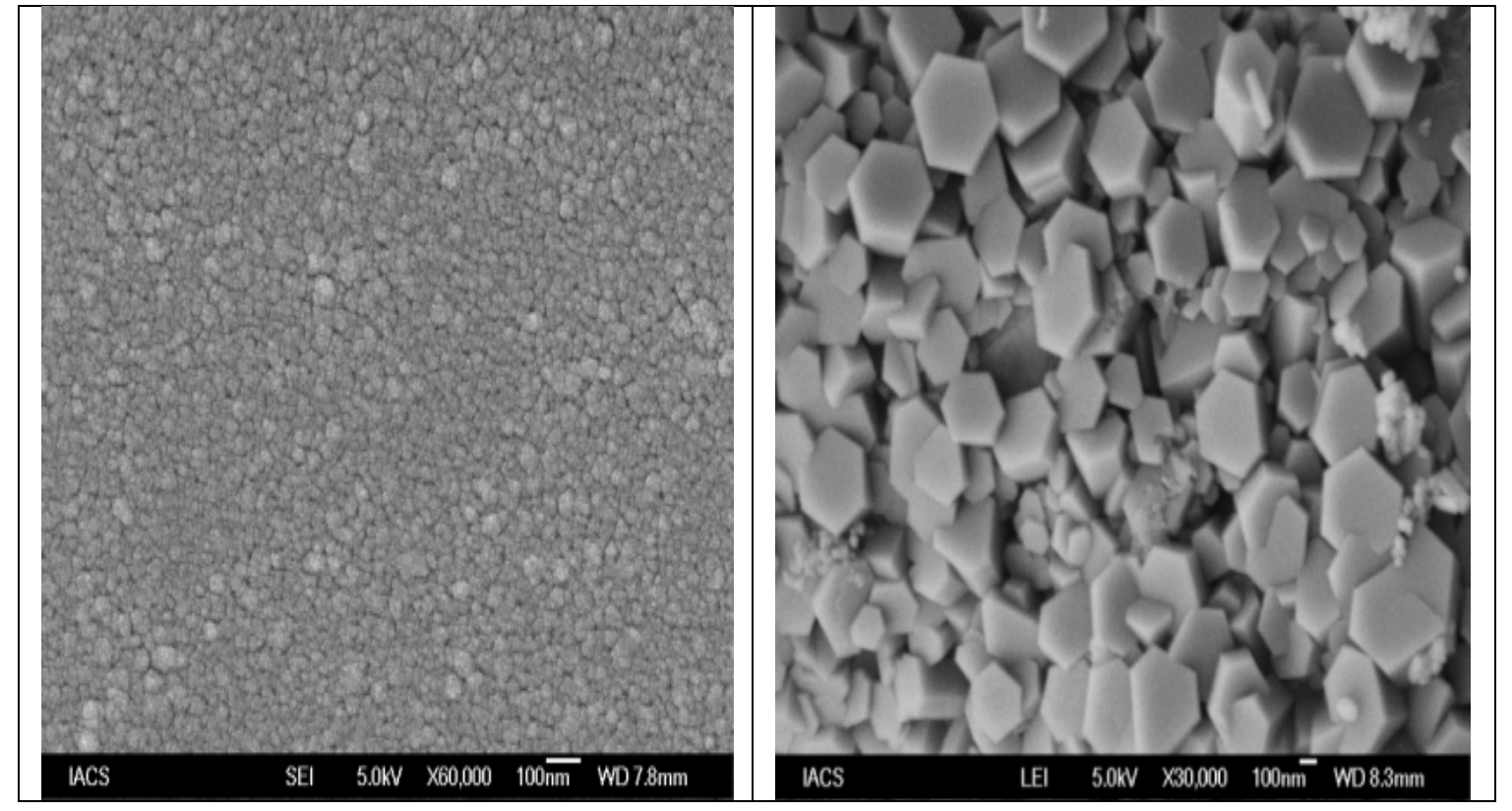

Figure 3: $\mathrm{SEM}$ images of seed $\mathrm{ZnO}$ and seed grow $\mathrm{ZnO}$.

Since a DSSC usually contains a series resistance, $R_{\mathrm{S}}$ and a shunt resistance, $R_{s h}$, the fill factor (FF) is introduced to count both effects. 
I.B. Karki et al. / BIBECHANA 11(1) (2014) 34-39: (Online Publication: March, 2014) p.37

$$
F F=\frac{P_{\max }}{I_{s c} \times V_{o c}}
$$

where $V_{\mathrm{oc}}$ is the open-circuit voltage and $I_{\mathrm{sc}}$ is the short-circuit current. The solar conversion efficiency of a DSSC can be calculated by,

$$
\eta=\frac{I_{s c} \times V_{o c} \times F F}{P_{\text {in }}}
$$

\subsection{The Equivalent Circuit Model of DSSC}

A solar cell is generally characterized using the equivalent circuit of the single diode model as shown in figure 4 and the relation between the current $I$ and the voltage $V$ is given by

$$
I=I_{p h}-I_{S}\left[\exp \left\{\frac{q\left(V+R_{S} I\right)}{A k_{B} T}\right\}-1\right]-\frac{V+R_{S} I}{R_{S h}}
$$

where $I_{p h}, I_{s}, R_{s}, R_{s h}, q, A, k_{B}$, and $T$ are the photocurrent, the saturation current of the diode, the series resistance, the shunt resistance, the electron charge, the ideality factor, the Boltzmann constant, and absolute temperature, respectively. Using equation (4) and fitting I-V curve, physical parameters of DSSC with Jamun dye have found and presented in table 1.

\subsection{Performance of the DSSC}

We have recorded $I-V$ characteristics of $\mathrm{ZnO}$ nanorods based DSSCs using natural dye Jamun with varied external resistances under illumination. Figure 5 shows the current voltage curve with fitting of dye based on DSSC solar cell. The physical parameters open-circuit voltage $\left(\mathrm{V}_{\mathrm{oc}}\right)$, short circuit current $\left(\mathrm{I}_{\mathrm{sc}}\right)$, maximum voltage $\left(\mathrm{V}_{\max }\right)$, maximum current $\left(\mathrm{I}_{\max }\right)$, values of DSSC cell with natural dye were calculated from figure 5 and fitted with the Eq. 4 for one diode equivalent circuit model (Fig. 4) by NewtonRaphson's method. As shown in Fig. 5, very good curve fitting, $\mathrm{R}^{2}=0.99$ and $\mathrm{Chi}^{2}=0.003$ were obtained in voltage range $0-0.55 \mathrm{~V}$ Results of curve fitting are given in Table-1.

The parasitic resistances (series and shunt) of DSSCs are important parameters that affect on efficiency of cell. The resulting parasitic resistances, series $\left(R_{s}\right)$ and shunt resistance $\left(R_{s h}\right)$ were evaluated from fitting

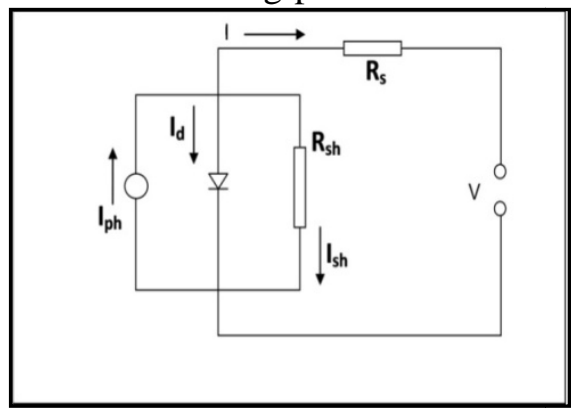
$I-V$ curve results. The fill factor (FF) for this cell using natural dye was also evaluated from the $I-V$ characteristics using equation (2) and finally the energy conversion efficiency $(\eta)$ were calculated using equation (3). All these results are presented in Table-1.

The cell parameters like Ideality factor (A), Fill factor (FF) and energy conversion efficiency $(\eta)$ of $\mathrm{ZnO}$ nanorod based DSSCs with natural dye were calculated and presented in Table-1, where values were calculated from current voltage curve of DSSC cell fabricated with natural Jamun dye.

Figure 4: Equivalent Circuit Diagram of DSSC.

Ideality factor indicates perfectness of the solar cell in the equivalent circuit, and it is 1.0 for a perfect cell. In our observation, an improvement in ideality factor (A) was observed 4.8 for Jamun dye based DSSC.

Table 1. The physical parameters open-circuit voltage $\left(\mathrm{V}_{\mathrm{oc}}\right)$, short circuit current $\left(\mathrm{I}_{\mathrm{sc}}\right)$, fill factor $(\mathrm{FF})$ and energy conversion efficiency $(\eta)$ values calculated from current voltage curve of natural dye DSSC cell.

\begin{tabular}{|c|c|c|c|c|c|c|c|c|}
\hline DSSC/Dye & $\mathbf{V}_{\text {oc }}(\mathbf{V})$ & $\begin{array}{c}\mathbf{I}_{\text {sc }} \\
(\mathbf{m A})\end{array}$ & $\begin{array}{c}\mathbf{I}_{\mathbf{0}} \\
(\boldsymbol{\mu} \mathbf{A})\end{array}$ & $\mathbf{F F}$ & $\begin{array}{c}\mathbf{R}_{\mathbf{s}} \\
(\boldsymbol{\Omega})\end{array}$ & $\left.\mathbf{R}_{\text {sh }} \mathbf{k} \boldsymbol{\Omega}\right)$ & $\begin{array}{c}\text { Ideality } \\
\text { Factor, } \mathbf{A}\end{array}$ & $\begin{array}{c}\boldsymbol{\eta} \\
(\boldsymbol{\%})\end{array}$ \\
\hline Jamun & 0.58 & 1.56 & 21 & 0.58 & 62 & 3.25 & 4.8 & 1.23 \\
\hline
\end{tabular}

After absorbing photon energy from the illuminated white light, the dye molecules in the DSSC become excited and inject electrons to the left side of $\mathrm{ZnO}$ nanorods as shown in figure 6. Due to favorable energy 
I.B. Karki et al. / BIBECHANA 11(1) (2014) 34-39: (Online Publication: March, 2014) p.38

difference, electron transfer occurs between the lowest unoccupied molecular orbital (LUMO) of the dye and the conduction band of $\mathrm{ZnO}$. The photogenerated electrons percolate rapidly through the $\mathrm{ZnO}$ nanorods and are collected by the conducting glass support. The highest occupied molecular orbital (HOMO) of the dye is energetically lower than the redox potential, $\mathrm{E}_{\text {redox }}$ of the iodide/triiodide couple. The energy difference provides the driving force for hole injection into the electrolyte.

Recombination of charge carrier is also minimized in such devices since transport of only one type of carrier (electron, in general) is energetically possible from the dye to the semiconductor. The reaction mechanisms (5-10) inside the DSSC solar cell are as follows:

$$
\begin{aligned}
& \text { Dye }+\mathrm{h} v \rightarrow \text { Dye }^{*} \\
& \mathrm{Dye}^{*}+\mathrm{ZnO} \rightarrow \mathrm{ZnO}^{\circ}+\mathrm{Dye}^{+} \\
& \mathrm{ZnO}^{-}+\mathbf{C E} \rightarrow \mathrm{ZnO}+\mathrm{CE}^{\circ}+\text { Energy } \\
& \mathrm{Dye}^{+}+\mathrm{I}^{-} \rightarrow \mathrm{Dye}+\mathrm{I}_{3}^{-} \\
& \mathrm{I}_{3}^{-}+\mathbf{C E} \rightarrow \mathrm{I}^{-}+\mathrm{CE} \\
& \text { Overall: hv (photon) } \rightarrow \text { Energy } \\
& (\mathrm{CE}=\text { Counter Electrode) }
\end{aligned}
$$

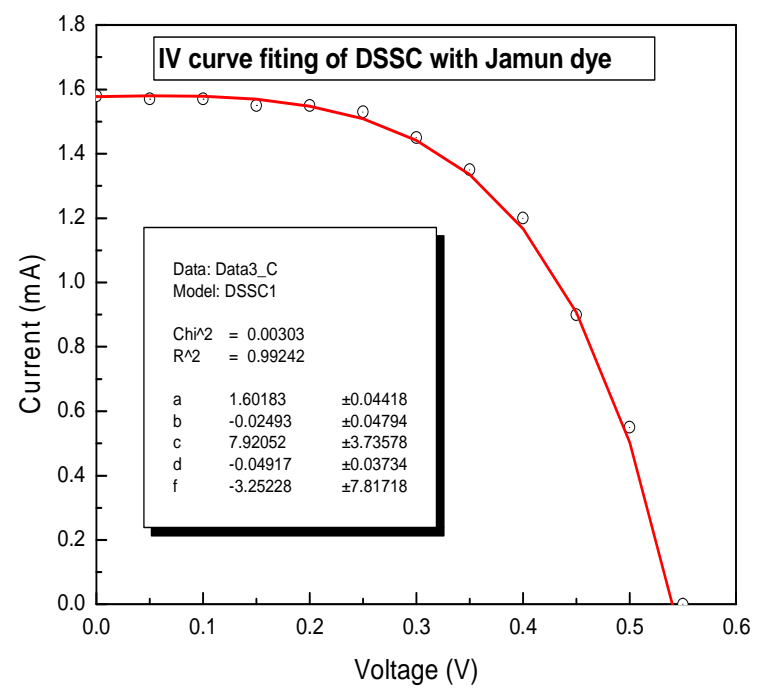

Figure 5: I-V curve fitting of DSSC with Jamun dye.

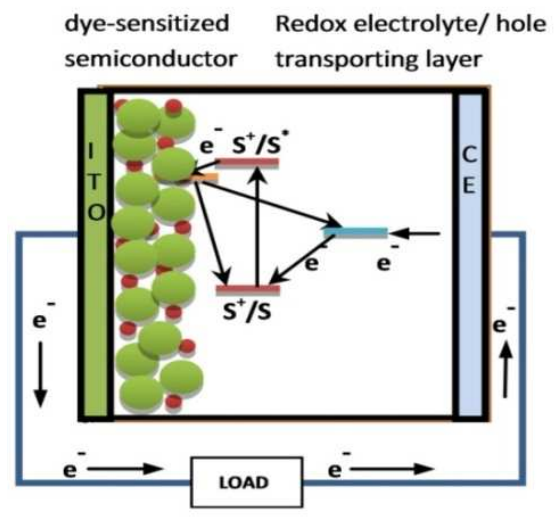

Figure 6: Working Principle of DSSC withdye.
The incident photon to current efficiency (IPCE) of the ITO coated $\mathrm{ZnO}$ based DSSC can affect on the collection efficiency. The recombination process is wavelength dependent because the penetration length of the light increases with the decreases of the absorption coefficient of the dye. In other words, illumination at wavelengths in which the dye absorption coefficient is low leads to the photo injection of electrons a long way from the current collector. If such a distance is longer than the electron diffusion length, these electrons are lost in recombination processes.

A fit of a one-diode model curve to a measured $I$ $V$ curve is shown in figure 5 . The $\mathrm{ZnO}$ nanorod based DSSC was prepared at the North Bengal University, Siliguri and is a $50 \mu \mathrm{m}$ thick cell with only $1.23 \%$ efficiency.

The fit parameters are given in the table 1 . The fit results give explanations of the low efficiency of

the DSSC: First of all, the dye content of this cell is too low, probably due to a non-optimized $\mathrm{ZnO}$ electrode. Secondly, the electron mobility has a relatively low value, probably due to poor electric contacts between the $\mathrm{ZnO}$ colloids. The high series resistance $\mathrm{R}_{\mathrm{s}}$ of 62 ohm resulting from the fit may be explained by a nonoptimized cell design and the fact that there are also contact resistances, which are included in the series resistances of the model. In this case, $\mathrm{R}_{\text {sh }}$ is too high for this DSSC and limits its performance. 
I.B. Karki et al. / BIBECHANA 11(1) (2014) 34-39: (Online Publication: March, 2014) p.39

\section{Conclusion}

Dye-sensitized solar cells (DSSCs) were assembled using extracts from various dyes as sensitizers for nanocrystalline $\mathrm{ZnO}$ photoelectrodes. Based on our investigation, it was found that Jamun possesses the photosensitization effect among other extracts of natural dyes studied. Natural dyes as alternative sensitizers for DSSCs are expected to be promising because of many reasons such as the simple preparation technique and low cost. The physical parameters of solar cell: series resistance $\left(\mathrm{R}_{\mathrm{s}}\right)$, ideality factor $(n)$, saturation current $\left(I_{s}\right)$, shunt resistance $\left(R_{\mathrm{sh}}\right)$ and photocurrent $\left(\mathrm{I}_{\mathrm{ph}}\right)$ were measured from measured current-voltage characteristics. $\mathrm{ZnO}$ thin films have been prepared on Indium tin oxide (ITO) glass substrate. These films were used to construct ITO/ZnO/Natural Dye/C/ITO, DSSC with natural anthocyanin sensitizer extracted from wild Jamun fruits. The cell shows open circuit voltage $\left(\mathrm{V}_{\text {oc }}\right)$ of $0.58 \mathrm{~V}$, short-circuit current $\left(\mathrm{I}_{\text {sc }}\right)$ of $1.66 \mathrm{~mA}$ and 0.58 fill factor $(\mathrm{FF})$ with an conversion efficiency $(\eta)$ of $1.23 \%$. Our research work will help understand the physics of low coast ZnO based DSSCs, predict the efficiency, and facilitate the development of future structures of natural dye based DSSCs.

\section{Acknowledgments}

The author I.B. Karki would like to thank the University Grants Commission (UGC), Nepal for PhD fellowship and National Academy of Science and Technology (NAST), Nepal; and Indian National Science Academy (INSA), India, for partial financial and technical support for this work. I.B. Karki is also grateful to the North Bengal University, Darjeeling, Siliguri, India and Central Department of Physics, Tribhuvan University, Kathmandu, Nepal for providing laboratory facilities and hospitality to carry out this work.

\section{References}

[1] G.E. Tulloch, J. Photoc. Photobiology A, 164 (2004) 209.

[2] A. Yella, H. Lee, H.N. Tsao, C. Yi, A.K. Chandiran, M.K. Nazeeruddin, E.W. Diau, C. Yeh, S.M. Zakeeruddin, M. Gratzel, Science, 334 (2011) 629.

[3] A.F. Nogueira, M.A. De Paoli, Sol. Energy Mater. Sol. Cells, 61 (2000) 127.

[4] B. O’Regan, M. Grätzel, Nature, 353 (1991) 737.

[5] G. Smestad, C. Bignozzi, R. Argazzi, Solar Energy Mater., 32 (1994) 259.

[6] Y. Chiba, A. Islam, Y. Watanabe, R. Komiya, N. Koide, L.Y. Han, Jpn. J. Appl. Phys., 45 (2006) L638.

[7] R. Buscaino, C. Baiocchi, C. Barolo, C. Medana, M. Grätzel, Md.K. Nazeeruddin, G. Viscardi, Inorg. Chim. Acta, 361 (2008) 798.

[8] L. M. Peter, J. Phys. Chem. C, 111 (2007) 6601.

[9] J. Bisquert, G. Garcia-Belmonte, F.J. Fabregat-Santiago, J. Solid State Electrochem. 3 (1999) 337.

[10] L. M. Peter, Phys. Chem. Chem. Phys., 9 (2007) 2630.

[11] E. Bellingeri, D. Marre, L. Pellegrino, I. Pallecchi, G. Canu, M. Vignolo, C. Bernini, A. S. Siri, Super lattices Microstructures, 38 (2005) 446.

[12] D. C. Look, Materials Science \& Engineering, B: Solid-State Materials for Advanced Technology B, 80 (2001) 383.

[13] U. Ozgur, Y,I. Alivov, C.Liu , A. Teke, M.A. Reshchikov, S. Dogan, J Appl Phys., 98 (2005) 8:04131.

[14] S.J. Pearton, D.P. Norton , Ip K, W. Heo, T. Steiner, Prog Mater Sci., 50 (2005) 293.

[15] M. R. Narayan, Renewable and Sustainable Energy Reviews, 16 (2012) 208.

[16] L. A. Kosyachenko, Solar Cells - Dye-Sensitized Devices, InTech Europe, University Campus STeP Ri Publication, First Edition 2011, ISBN 978-953-307-735-2.

[17] I. B. Karki, J. J. Nakarmi, P. K. Mandal, S. Chatterjee, Nepal Journal of Science and Technology, 13 (2012) 179.

[18] N.J. Cherepy, G.P. Smestad, M. Grätzel, J.Z. Zhang, J. Phys. Chem. B, 101 (1997) 9342.

[19] B. Pradhan, S. Kumar, B. Amal, J. Pal, Sol. Energy Mater. Sol. Cells, 91 (2007) 769. 